\section{BRAZIULIAN JOURNAL \\ OF MEDICAL AND BIOLOGICAL RESEARCH}

www.bjournal.com.br
ISSN 1414-431X

Volume 45 (12) 1102-1340 December 2012

\section{BIOMIDICAL SCIENCES}

AND

CLINICAL INVESTIGATION

Braz J Med Biol Res, December 2012, Volume 45(12) 1301-1307

doi: $10.1590 / 1414-431 X 20122586$

Clinical outcome of protein-energy malnourished patients in a Brazilian university hospital

T.A.S. Pasquini, H.D. Neder, L. Araújo-Junqueira and D.A. De-Souza

The Brazilian Journal of Medical and Biological Research is partially financed by

\section{욛NPq}

Ministério

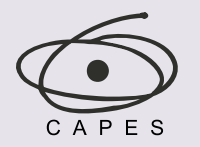

Ministério da Educação

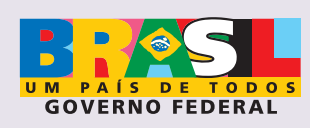

DTAPESP

Institutional Sponsors

๑ SHIMADZu

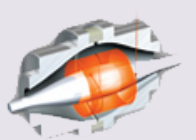

GOVERNO FEDERAL
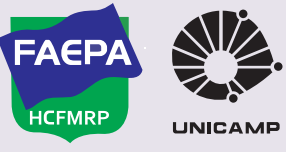

UNICAMP 


\title{
Clinical outcome of protein-energy malnourished patients in a Brazilian university hospital
}

\author{
T.A.S. Pasquini ${ }^{1}$, H.D. Neder ${ }^{2}$, L. Araújo-Junqueira ${ }^{1}$ and D.A. De-Souza ${ }^{1,3}$ \\ ${ }^{1}$ Programa de Pós-Graduação em Ciências da Saúde, Faculdade de Medicina, \\ Universidade Federal de Uberlândia, Uberlândia, MG, Brasil \\ 2Instituto de Economia, Universidade Federal de Uberlândia, Uberlândia, MG, Brasil \\ ${ }^{3}$ Departamento de Clínica Médica e Curso de Nutrição, Faculdade de Medicina, \\ Universidade Federal de Uberlândia, Uberlândia, MG, Brasil
}

\begin{abstract}
Protein-energy malnutrition (PEM) is a treatable disease with high prevalence among hospitalized patients. It can cause significant increases in the duration of hospitalization and costs. PEM is especially important for health systems since malnourished patients present higher morbidity and mortality. The objective of the present study was to assess the evolution of nutritional status (NS) and the effect of malnutrition on clinical outcome of patients at a public university hospital of high complexity in Brazil. Patients hospitalized in internal medicine $(n=54)$, oncology $(n=43)$, and infectious diseases $(n=12)$ wards were included. NS was evaluated using subjective global assessment up to $48 \mathrm{~h}$ after admission, and thereafter at intervals of 4-6 days. On admission, patients $(n=109)$ were classified as well-nourished $(n=73)$, moderately malnourished or at risk of malnutrition $(n=$ 28 ), and severely malnourished $(n=8)$. During hospitalization, malnutrition developed or worsened in 11 patients. Malnutrition was included in the clinical diagnosis of only $5 / 36$ records $(13.9 \%$ of the cases, $P=0.000)$. Nutritional therapy was administered to only 22/36 of the malnourished patients; however, unexpectedly, 6/73 well-nourished patients also received commercial enteral diets. Complications were diagnosed in $28 / 36$ malnourished and $9 / 73$ well-nourished patients $(P=0.000)$. Death occurred in $12 / 36$ malnourished and $3 / 73$ well-nourished patients $(P=0.001)$. A total of $24 / 36$ malnourished patients were discharged regardless of NS. In summary, malnutrition remains a real problem, often unrecognized, unappreciated, and only sporadically treated, even though its effects can be detrimental to the clinical course and prognosis of patients. The amount of public and private funds unnecessarily dispersed because of hospital malnutrition is significant.
\end{abstract}

Key words: Protein-energy malnutrition; Hospital malnutrition; Assessment of nutritional status; Evolution of nutritional status; Nutritional therapy; Subjective global assessment

\section{Introduction}

Hospital protein-energy malnutrition (PEM) occurs worldwide (1-3). Studies conducted in Latin America (4) and in Brazil (5) have demonstrated PEM in approximately $50 \%$ of hospitalized patients. The impairment of the nutritional status of hospitalized patients is closely associated with, among other factors, the incorrect execution of basic actions in nutritional care (6-8). Despite the demonstration in clinical studies of a high prevalence of malnutrition among hospitalized patients, in clinical practice PEM is not yet recognized as an illness and not always diagnosed (9). Several reports have shown that the presence of PEM results in an impairment of the response to therapeutic planning (10), inefficiency and delay in wound healing and a decrease in wound bursting strength related to sutures, development of pressure ulcers $(11,12)$, as well as increases in the frequency of infectious and noninfectious complications (13), the duration of hospitalization, and the mortality rate $(14,15)$. In addition, it has also been established that the impact of hospital malnutrition on health and social costs is significant (16). According to Correia and Waitzberg (17), in developing countries, hospital costs for the public health system were on average $60 \%$ higher for the hospitalization and treatment of malnourished patients compared to well-nourished ones.

The objective of this observational prospective study was to analyze the evolution of nutritional status, the frequency of malnutrition reported in the clinical diagnoses and the associations between nutritional status and the administra-

Correspondence: D.A. De-Souza, Faculdade de Medicina, Universidade Federal de Uberlândia, Av. Pará, 1720, Bloco 2U, Sala 23, 38405-320 Uberlândia, MG, Brasil. Fax: +55-34-3232-8620. E-mail: daureas@ufu.br

Received August 4, 2012. Accepted September 10, 2012. Available online December 17, 2012. Published December 17, 2012. 
tion of nutritional therapy, the development of complications and the clinical outcome of patients in a public teaching hospital of high complexity in Brazil.

\section{Patients and Methods}

\section{Patients}

Patients hospitalized on the wards of internal medicine (a total of 52 hospital beds), oncology (a total of 24 hospital beds) and infectious diseases (a total of 16 hospital beds) of Hospital de Clínicas, Universidade Federal de Uberlândia (a total of 510 hospital beds), between 09/01/2009 and $10 / 31 / 2009$, were included in the study. To avoid situations compromising nutritional status associated with medium or large surgical interventions, surgical patients were excluded. The study was approved by the Research Ethics Committee of the Universidade Federal de Uberlândia, MG, Brazil (research protocol No. CEP/UFU 120/09) and all participants gave written informed consent.

\section{Assessment of nutritional status}

Nutritional status was assessed by the same professional throughout the study. The subjective global assessment (SGA) questionnaire (18) was applied during the first $48 \mathrm{~h}$ of hospitalization and then at 4-6, 10-12, and 16-18 days following admission. For patients with a longer hospital stay, the evaluations were carried out 4 to 6 days after the previous assessment.

\section{Subjective global assessment}

The SGA originally proposed by Detsky et al. (18) is a method for screening nutritional status, which, in a rapid and simple way, determines if the availability of nutrients is impaired due to decreased food intake, poor digestion or absorption; whether the nutritional status disorder has led to effects on the function of organs or on body composition, and whether the disease of the patient influences the need for energy and nutrients. The physical examination determines whether the PEM has reduced fat and/or muscle mass and whether the patient presents edema in the lower extremities, sacral region and/or ascites. Information from the clinical history and physical examination is assigned numerical values subjectively in order to classify the patient as well-nourished (SGA A), moderately malnourished or at risk of malnutrition (SGAB) or severely malnourished (SGA C). The ability of the SGA to indicate malnutrition-associated risks of poor outcome has been validated by Raslan et al. (19).

\section{Data collection}

Data concerning gender, age, and clinicalsurgical diagnosis were collected at the time of hospital admission. During hospitalization, information related to established nutritional therapy, diagnosis of infectious (pneumonia, sepsis, urinary tract infection) and noninfectious complications (anemia, pressure ulcer, refeeding syndrome), and other clinical/surgical diseases was obtained daily by consultation of the patient's record. At the time of hospital discharge, information regarding the length of hospitalization, other clinical/surgical diagnoses and outcome (discharge or death) was collected.

\section{Statistical analysis}

The descriptive statistics of the data collected were used to characterize the patients. The two-sample test of proportion for large samples was used for the proportion comparison between groups. A multivariate logistic regression model was also used to evaluate the impact of some factors on the complication and death risk, as well as the binomial test for proportion values. Statistical analysis was performed using the Stata software (USA), version 12.0. The level of significance was set at $P<0.05$.

\section{Results}

A total of 109 patients hospitalized on the internal medicine $(n=54)$, oncology ( $n=43)$, and infectious diseases ( $=12$ ) wards were prospectively included in the study. During the first $48 \mathrm{~h}$ of hospitalization, patients were classified as well-nourished $(n=73)$, moderately malnourished or at risk of malnutrition ( $n=28)$, and severely malnourished $(n=8)$, i.e., a prevalence of malnutrition of $33.2 \%$ (Table 1 ). The relative frequency of malnutrition among patients hospitalized on the oncology ward (0.535) was significantly higher than among the patients hospitalized on the internal medicine ward $(0.148 ; P=0.000)$. Similar results were observed in the comparison between the infectious diseases ward $(0.416)$ and the internal medicine ward $(0.148 ; P=0.034)$. There was no significant difference in the relative frequency of malnutrition between patients hospitalized on the oncology and infectious diseases wards $(P=0.469)$. Among the patients evaluated as malnourished $(n=36)$, PEM was

Table 1. Distribution of patients in this study as a function of hospital ward, age, gender, and nutritional status according to the Subjective Global Assessment (SGA) at the Hospital de Clínicas, Universidade Federal de Uberlândia.

\begin{tabular}{|c|c|c|c|c|c|c|c|}
\hline \multirow[t]{2}{*}{ Ward } & \multirow[t]{2}{*}{ Patients } & \multirow[t]{2}{*}{ Age (years) } & \multicolumn{2}{|c|}{ Gender (n) } & \multicolumn{3}{|c|}{ SGA } \\
\hline & & & $\mathrm{F}$ & M & $A$ & $\mathrm{~B}$ & C \\
\hline Internal medicine & $54(49.5 \%)$ & $54.1 \pm 17.8$ & 37 & 17 & 46 & 6 & 2 \\
\hline Oncology & $43(39.5 \%)$ & $52.1 \pm 18.2$ & 26 & 17 & 20 & 18 & 5 \\
\hline Infectious diseases & $12(11.0 \%)$ & $38.1 \pm 16.0$ & 6 & 6 & 7 & 4 & 1 \\
\hline Total & $109(100 \%)$ & & 69 & 40 & 73 & 28 & 8 \\
\hline
\end{tabular}

Data for patients, gender and SGA are reported as number and data for age are reported as means $\pm S D$. SGAA = well-nourished; SGA B = moderately malnourished or at risk of malnourishment; SGA C = severely malnourished. 
Table 2. Inclusion of malnutrition in the clinical diagnoses of the records of patients according to the hospitalization ward at the Hospital de Clínicas, Universidade Federal de Uberlândia.

\begin{tabular}{lcccc}
\hline Wards & $\begin{array}{c}\text { Patients assessed as } \\
\text { malnourished by SGA }\end{array}$ & \multicolumn{3}{c}{ Clinical diagnosis } \\
\cline { 3 - 5 } & & & & \\
\cline { 3 - 5 } & & $\begin{array}{c}\text { Non-inclusion of the } \\
\text { malnutrition disease }\end{array}$ & $\begin{array}{c}\text { Inclusion of the } \\
\text { malnutrition disease }\end{array}$ & $\mathrm{P}$ \\
\hline Internal medicine & 8 & 21 & 2 \\
Oncology & 23 & 4 & 2 & 1 \\
Infectious diseases & 5 & $31(86.1 \%)$ & $5(13.9 \%)$ & $0.000^{*}$ \\
Total & $36(100 \%)$ & &
\end{tabular}

SGA = Subjective Global Assessment. Malnourished = moderately malnourished or at risk of malnutrition + severely malnourished (SGA B + SGA C). ${ }^{*} \mathrm{P}<0.05$ (binomial test for proportion differences).

Table 3. Periodic assessment of nutritional status according to the Subjective Global Assessment (SGA) and clinical outcome of patients.

\begin{tabular}{|c|c|c|c|c|c|c|c|c|c|c|c|c|}
\hline & \multicolumn{3}{|c|}{ SGAA } & \multicolumn{3}{|c|}{ SGA B } & \multicolumn{3}{|c|}{ SGA C } & \multicolumn{3}{|c|}{ Total } \\
\hline & Hospitalized & Discharge & Death & Hospitalized & Discharge & Death & Hospitalized & Discharge & Death & Hospitalized & Discharge & Death \\
\hline Up to $48 \mathrm{~h}$ & 73 & 0 & 0 & 28 & 0 & 0 & 8 & 0 & 0 & 109 & 0 & 0 \\
\hline 4-6 days & $68^{a}$ & 5 & 0 & $27 \mathrm{~d}, \mathrm{e}$ & 0 & 0 & 9 & 0 & 0 & 104 & 5 & 0 \\
\hline $10-12$ days & $46^{b}$ & 21 & 0 & $23^{f}$ & 3 & 2 & 6 & 3 & 0 & 75 & 27 & 2 \\
\hline $16-18$ days & 26 & 19 & 2 & $10 \mathrm{~g}, \mathrm{~h}$ & 8 & 4 & 41 & 1 & 1 & 40 & 28 & 7 \\
\hline $22-24$ days & $19^{c}$ & 6 & 0 & $10^{i}$ & 0 & 0 & 5 & 0 & 0 & 34 & 6 & 0 \\
\hline 28-30 days & 12 & 7 & 0 & $8^{j}$ & 0 & 2 & 5 & 0 & 0 & 25 & 7 & 2 \\
\hline $34-36$ days & 8 & 5 & 0 & 4 & 2 & 1 & 2 & 2 & 1 & 14 & 9 & 2 \\
\hline 40-42 days & 5 & 2 & 1 & 4 & 0 & 0 & 1 & 0 & 1 & 10 & 2 & 2 \\
\hline $46-48$ days & 5 & 0 & 0 & 3 & 1 & 0 & 0 & 1 & 0 & 8 & 2 & 0 \\
\hline $52-54$ days & 1 & 4 & 0 & $2^{k}$ & 0 & 0 & 1 & 0 & 0 & 4 & 4 & 0 \\
\hline $60-62$ days & 1 & 0 & 0 & 1 & 1 & 0 & 1 & 0 & 0 & 3 & 1 & 0 \\
\hline $66-68$ days & 0 & 1 & 0 & 1 & 0 & 0 & 1 & 0 & 0 & 2 & 1 & 0 \\
\hline 72 days & 0 & 0 & 0 & 0 & 1 & 0 & 0 & 1 & 0 & 0 & 2 & 0 \\
\hline Total & 0 & 70 & 3 & 0 & 16 & 9 & 0 & 8 & 3 & 0 & 94 & 15 \\
\hline
\end{tabular}

SGAA = well-nourished; SGA B = moderately malnourished or at risk of malnourishment; SGA $C=$ severely malnourished. Modification of nutritional status: $a=3$ patients SGA A to SGA B; $b=3$ patients SGA A to SGA B; $c=1$ patient SGA A to SGA B; $d=3$ patients SGA B to $S G A A ; e=1$ patient SGA B to SGA $C ; f=2$ patients SGA B to SGAA; $g=1$ patient SGA $B$ to $S G A A ; h=1$ patient $S G A B$ to $S G A$; $\mathrm{i}=1$ patient SGA B to SGA C; $\mathrm{j}=1$ patient SGA B to SGA $; \mathrm{k}=1$ patient SGA B to SGA $C ; \mathrm{I}=1$ patient SGA C to SGA B.

included in the list of clinical diagnoses in only five records (13.9\% of cases, $\mathrm{P}=0.000$; Table 2 ).

During the period of sequential evaluation of nutritional status, some well-nourished patients progressed to moderate malnutrition $(n=7)$, some patients with moderate malnutrition progressed to severe malnutrition $(n=4)$ or to well-nourished status ( $n=8)$, and 1 patient with severe malnutrition progressed to moderate malnutrition (Table 3). Among the 36 patients classified with malnutrition (SGA B + SGAC), only $22(61.1 \%$ ) received nutritional therapy, i.e., a total of $14(38.8 \%)$ patients evaluated as moderately or severely malnourished did not receive treatment for recovery of nutritional status. In contrast to these results, nutritional therapy was administered to 6 patients $(8.2 \%$, total of 67 patients) classified as well-nourished (Figure 1).

Infectious and noninfectious complications were identified in 28/36 malnourished patients (77.8\%) and in $9 / 73$ patients evaluated as well-nourished at admission (12.3\%; $P$ $=0.000$ ). Furthermore, according to the results of a logistic model, malnourished patients presented a marked increase in the risk of developing complications when compared with well-nourished patients (odds ratio $=19.80$ ), regardless of the ward of hospitalization (Figure 2). Among well-nourished patients the relative frequency of complications was higher in patients hospitalized on the oncology (4/20) and infectious diseases wards (2/7) than on the internal medicine ward (3/46; Figure 2).

A total of 70 patients sequentially evaluated as well- 

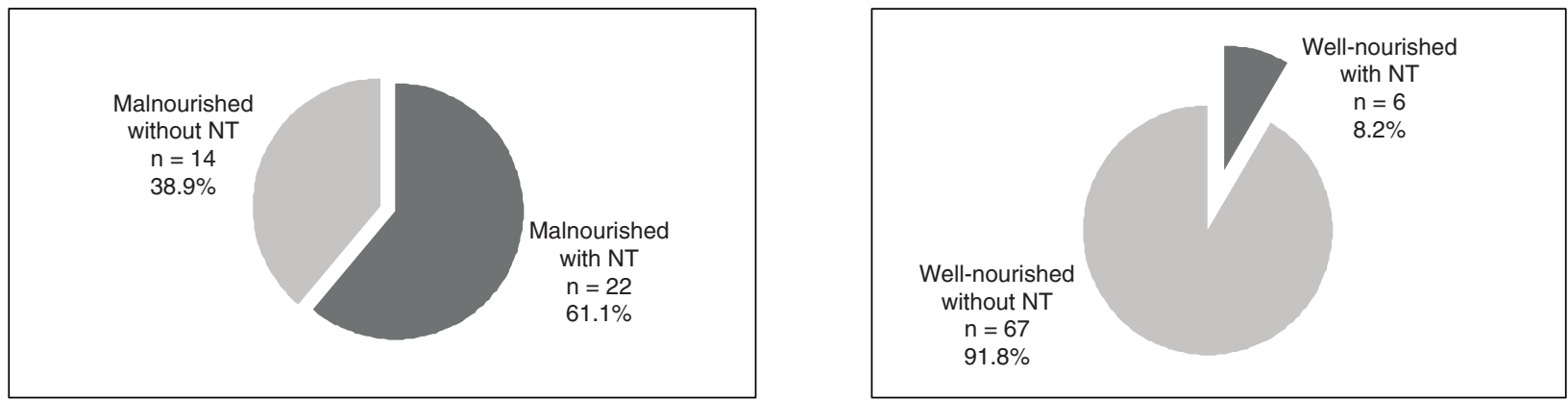

Figure 1. Administration of Nutritional Therapy (NT) as a function of nutritional status. Nutritional status was assessed by Subjective Global Assessment (SGA) within the first $48 \mathrm{~h}$ of hospitalization. SGA A = well-nourished; SGA B + SGA C = malnourished. Data are reported as number of patients.

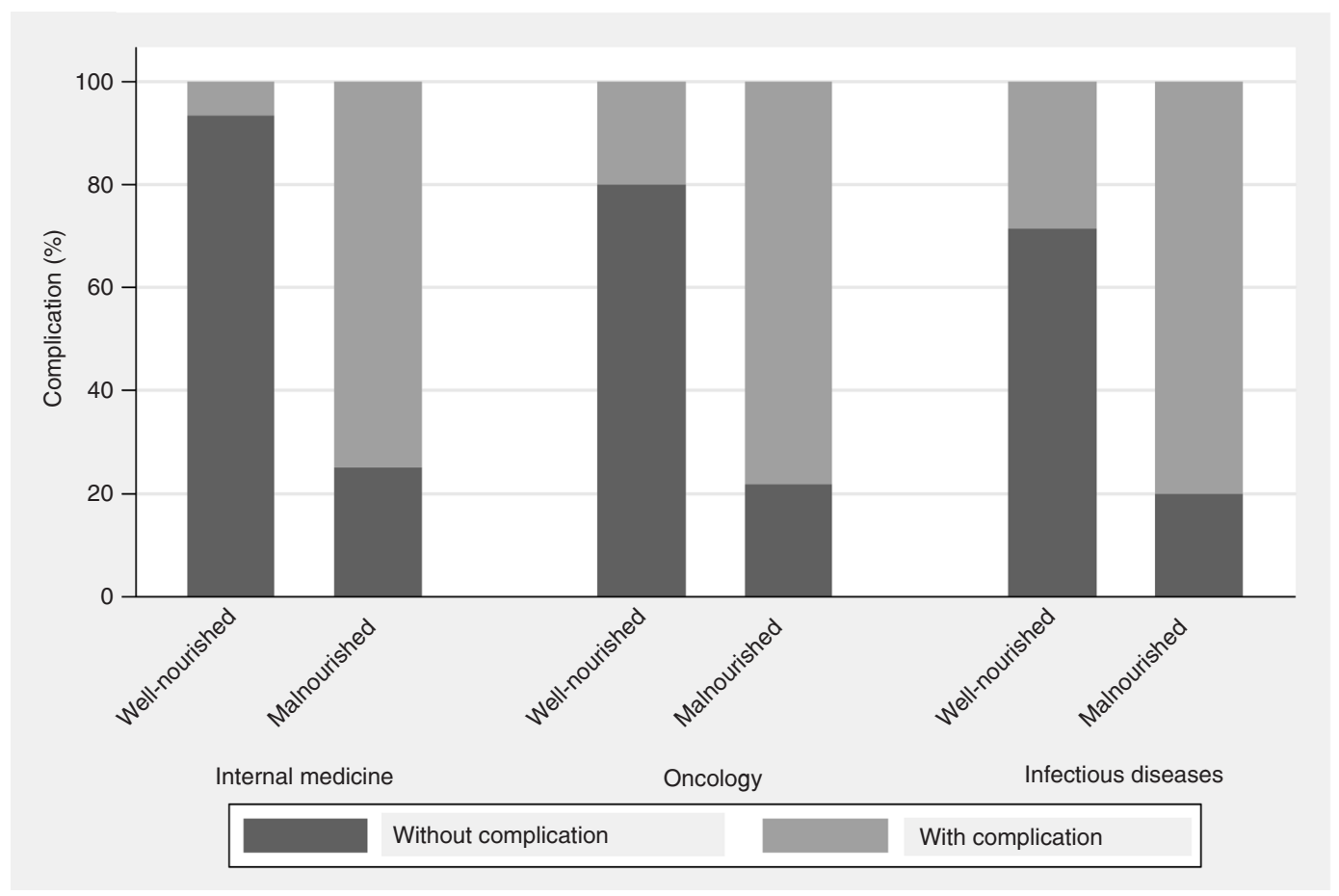

Figure 2. Frequency of infectious and noninfectious complications as a function of nutritional status. Nutritional status was assessed by Subjective Global Assessment (SGA) within the first $48 \mathrm{~h}$ of hospitalization. SGAA= wellnourished; SGA B + SGA C = malnourished. Data are reported as percent of patients.

nourished (95.9\% of cases, $n=73)$, as well as 24 patients at risk for or with moderate malnutrition, or with severe malnutrition $(66.6 \%$ of cases, $n=36)$ were discharged from the hospital. Hospital discharge without treatment for nutritional status recovery, or with only initial treatment, prevented the calculation of the effect of nutritional status on hospital stay $(15.3 \pm 14.1$ vs $17.9 \pm 11.0$ days for wellnourished and malnourished patients, respectively).

The death rate was significantly higher among patients evaluated as moderately or severely malnourished during the hospital stay ( $n=12,33.3 \%$ of cases) than among pa- tients assessed as well-nourished $(n=3,4.1 \%$ of cases; $P$ $=0.001$ ) (Figure 3). Thus, malnourished patients presented a higher risk of death compared to well-nourished patients (odds ratio $=3.03$ ). According to the results of the estimation of a logistic model, an increase of the probability of death was observed among patients hospitalized on the oncology (odds ratio $=6.67$ ) and infectious diseases (odds ratio $=1.68)$ wards compared to patients hospitalized on the internal medicine ward. The discharge of malnourished patients may also have interfered with the demonstration of the association between malnutrition and death. This 


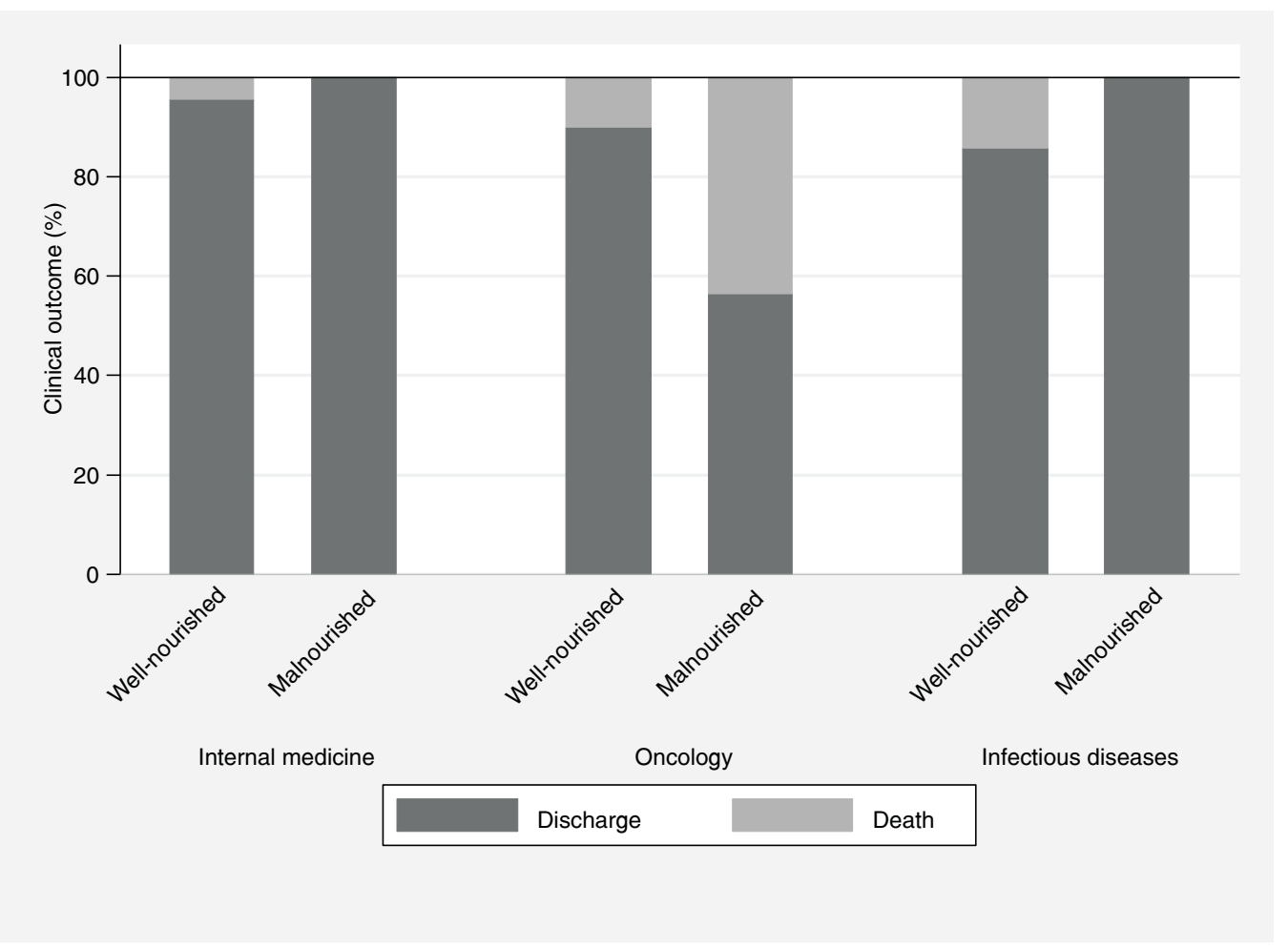

Figure 3. Clinical outcome as a function of nutritional status. Nutritional status was assessed by Subjective Global Assessment (SGA) within the first $48 \mathrm{~h}$ of hospitalization. SGA A = well-nourished; SGA B + SGA C = malnourished. Data are reported as percent of patients.

interpretation is based on the demonstration of deaths among well-nourished patients hospitalized on the internal medicine, oncology and infectious diseases wards. However, among the malnourished patients no deaths occurred in the wards of internal medicine and infectious diseases (Figure 3).

\section{Discussion}

We demonstrated that $33.2 \%$ of the patients $(n=36)$ evaluated within the first $48 \mathrm{~h}$ of admission had PEM. Although 8 patients showed improvement in their nutritional status, during hospitalization 7 new cases of malnutrition were diagnosed, as well as 4 patients presenting further deterioration of nutritional status. Despite the increased morbidity and mortality associated with malnutrition, the diagnosis of malnutrition per se did not prevent patient discharge.

The development of the capacity to prevent, identify and treat malnutrition is a major concern among various international organizations $(8,20)$. In Brazil, the establishment of the Multidisciplinary Team of Nutritional Therapy in 1998 by the National Agency of Health Surveillance, Ministry of Health (21), was an important step in the attempt to resolve the hospital malnutrition issue. However, this initiative has not yet significantly reduced the frequency of PEM in hospitals. Clinical studies have demonstrated that Latin America (4) and Brazil (5) have the highest published rates of PEM worldwide (2). The lack of updating, availability and interaction among members of the Multidisciplinary Team of Nutritional Therapy and the lack of emphasis on nutritional issues of the patients among health care professionals (including the assessment of nutritional status and the implementation of nutritional therapy), are some of the reasons for the increased frequency of PEM among hospitalized patients $(6,7)$. The worsening of nutritional status in hospitalized patients is also closely associated with numerous aspects of the hospital routine (22). Usually the body weight and height of patients are not recorded; the daily calculation of rest/intake is not routinely performed, and the outcome of nutritional status of malnourished patients or of those at nutritional risk is not assessed. Thus, it is possible to conclude that there is not enough standardization of nutritional therapy protocols (21) for the problem of hospital malnutrition to be resolved. Due to the complexity of issues related to the nutritional care of hospitalized patients, the diagnosis of the actions of the professionals of different categories that contribute to the development or exacerbation of PEM among Brazilian patients is necessary, as already done in hospitals of some developed countries $(6,9,20)$. The 
implementation of isolated actions is insufficient to resolve the problem of hospital malnutrition.

It has been repeatedly demonstrated in the literature (23-25) and established in the Guidelines of the American Society for Parenteral and Enteral Nutrition (ASPEN) and European Society for Parenteral and Enteral Nutrition (ESPEN) that nutritional therapy for hospitalized patients should be effectively administered to prevent and/or reduce the installation of malnutrition or to correct the nutritional changes already installed in malnourished patients $(26,27)$. However, this approach cannot be confirmed by our results. In the present study, hospital discharge of individuals with PEM was a common practice adopted in a systematic way, regardless of the degree of malnutrition of the patient. The lack of recognition of PEM as a treatable disease and with a real possibility of resolution may be one of the causes of this conduct, i.e., the diagnosis of malnutrition is not a sufficient reason for maintaining the hospitalization of the patient. Furthermore, the lack of inclusion of PEM among the diseases that require hospitalization, as well as the limited number of beds available in the Brazilian public health system, are also causes of questionable practices, such as the discharge of malnourished patients.

A practice that limited the identification of the effect of enteral or parenteral nutrition in the present study was the fact that among the patients assessed as malnourished only $61.1 \%(n=22)$ received nutritional therapy. Another relevant and disturbing result was the significant number of individuals classified as well-nourished who received nutritional therapy $(8.2 \%, n=6)$, especially when considering that the study evaluated patients admitted to a public university hospital with limited financial resources.

Another result of concern identified in this study was the failure of the health team to include the diagnosis of malnutrition in the clinical diagnoses of the patients. It is important to emphasize that if the nutritional status is not diagnosed, then actions for the treatment and prevention of malnutrition are not implemented, resulting in the patient being exposed to all the complications inherent to the presence of nutritional deficits $(5,7,8)$. Confirming data in the literature $(10,13,20,28,29)$, we showed that malnourished patients have more complications and more frequently progress to death when compared to well-nourished patients. In the present study, malnourished patients had a 19.8 times increased odds ratio to develop complications and a 3.3 times increased odds ratio of death compared to well-nourished patients. These results are of concern and, to our knowledge, this is the first report that a large number of malnourished patients did not have the disease included in their clinical diagnosis, did not receive nutritional therapy, and were discharged regardless of their nutritional status.

Malnutrition is an authentic and treatable disease, often unrecognized, unappreciated and only sporadically treated, although its effects are highly detrimental to the clinical course and prognosis of patients (22). Given the influence of nutritional status on the clinical outcome, already established in the ASPEN and ESPEN Guidelines $(25,26)$, it is essential to investigate the clinical conditions associated with compromised nutritional status in an attempt to identify if the insufficient intake/missing energy and nutrients are the causal factor, if nutritional deficiencies are due solely to injury, or if both factors are operative. The prevalence of malnutrition per se identified in this study illustrates the importance of an effective Nutritional Therapy Multiprofessional Team in the hospital that is updated and committed to the patient's nutritional care. The presence of malnutrition observed by trained professionals requires an appropriate conduct for the recovery of nutritional status (27), i.e., discharge of malnourished patients must be considered at least to be a questionable conduct. Since in many hospitals the basic equipment/materials needed for the recovery of nutritional status are usually available, but there is a limitation of hospital beds provided by the Brazilian public health system, it is essential to determine which patients would potentially benefit more from continued hospitalization. More specifically, patients with mild or even moderate proteinenergy malnutrition, low or absent metabolic stress, minimal or absent losses of food and/or nutrients (absence/control of diarrhea and/or vomiting, absence/control of systemic infectious and/or liver/kidney diseases, absence/control of disabsorptive syndromes, among others), with the availability of a caregiver and sufficient financial conditions to purchase the products for a recommended diet, as a rule, can be monitored as outpatients. However, for patients with severe malnutrition, with high metabolic stress, presenting disabsorptive syndromes or involvement of organs/systems related to metabolism, in the extreme age groups (children and elderly), with poor financial conditions and without a caregiver, the indication of hospitalization or a longer hospital stay may result in patient survival.

It should be recognized that the presence of proteinenergy malnutrition is not a question of aesthetics, but is a treatable disease that increases morbidity and mortality. It is necessary to carefully evaluate the clinical status of each patient and what is necessary to establish a program of nutritional therapy with the best cost/benefit ratio. It is hoped that the results shown in this study be used as a warning for the reassessment and development of more appropriate behavior for the nutritional care of hospitalized patients.

\section{Acknowledgments}

We thank the dietitian Valeria Néris Araújo for her cooperation in collecting and organizing the data. 


\section{References}

1. Pirlich M, Schutz T, Norman K, Gastell S, Lubke HJ, Bischoff SC, et al. The German hospital malnutrition study. Clin Nutr 2006; 25: 563-572.

2. Norman K, Pichard C, Lochs H, Pirlich M. Prognostic impact of disease-related malnutrition. Clin Nutr 2008; 27: 5-15.

3. Imoberdorf R, Meier R, Krebs P, Hangartner PJ, Hess B, Staubli $\mathrm{M}$, et al. Prevalence of undernutrition on admission to Swiss hospitals. Clin Nutr 2010; 29: 38-41.

4. Correia MI, Campos AC. Prevalence of hospital malnutrition in Latin America: the multicenter ELAN study. Nutrition 2003; 19: 823-825.

5. Waitzberg DL, Caiaffa WT, Correia MI. Hospital malnutrition: the Brazilian national survey (IBRANUTRI): a study of 4000 patients. Nutrition 2001; 17: 573-580.

6. European Forum. Food and nutritional care in hospitals: acting together to prevent undernutrition. Strasbourg, Council of Europe, November 2001. http://www.coe.int/T/E/Social_Cohesion/socp/Defproceedingshospitals.pdf2008.

7. Butterworth CE. The skeleton in the hospital closet. Nutrition Today 1974; 9: 4-9.

8. Klein S, Kinney J, Jeejeebhoy K, Alpers D, Hellerstein M, Murray M, et al. Nutrition support in clinical practice: review of published data and recommendations for future research directions. National Institutes of Health, American Society for Parenteral and Enteral Nutrition, and American Society for Clinical Nutrition. JPEN J Parenter Enteral Nutr 1997; 21: 133-156.

9. Elia M, Zellipour L, Stratton RJ. To screen or not to screen for adult malnutrition? Clin Nutr 2005; 24: 867-884.

10. Chandra RK. Nutrition and the immune system: an introduction. Am J Clin Nutr 1997; 66: 460S-463S.

11. Banks MD, Graves N, Bauer JD, Ash S. The costs arising from pressure ulcers attributable to malnutrition. Clin Nutr 2010; 29: 180-186

12. lizaka S, Okuwa M, Sugama J, Sanada H. The impact of malnutrition and nutrition-related factors on the development and severity of pressure ulcers in older patients receiving home care. Clin Nutr 2010; 29: 47-53.

13. Borelli P, Barros FE, Nakajima K, Blatt SL, Beutler B, Pereira $\mathrm{J}$, et al. Protein-energy malnutrition halts hemopoietic progenitor cells in the G0/G1 cell cycle stage, thereby altering cell production rates. Braz J Med Biol Res 2009; 42: 523530.

14. McWhirter JP, Pennington CR. Incidence and recognition of malnutrition in hospital. BMJ 1994; 308: 945-948.

15. Sanchez FF, Faganello MM, Tanni SE, Lucheta PA, Pelegrino NG, Hasegawa SH, et al. Anthropometric midarm measurements can detect systemic fat-free mass depletion in patients with chronic obstructive pulmonary disease. Braz J Med Biol Res 2011; 44: 453-459.
16. Rice N, Normand C. The cost associated with diseaserelated malnutrition in Ireland. Public Health Nutr 2012; 15: 1966-1972.

17. Correia MI, Waitzberg DL. The impact of malnutrition on morbidity, mortality, length of hospital stay and costs evaluated through a multivariate model analysis. Clin Nutr 2003; 22: 235-239.

18. Detsky AS, McLaughlin JR, Baker JP, Johnston N, Whittaker $S$, Mendelson RA, et al. What is subjective global assessment of nutritional status? JPEN J Parenter Enteral Nutr 1987; 11: 8-13.

19. Raslan M, Gonzalez MC, Torrinhas RS, Ravacci GR, Pereira JC, Waitzberg DL. Complementarity of Subjective Global Assessment (SGA) and Nutritional Risk Screening 2002 (NRS 2002) for predicting poor clinical outcomes in hospitalized patients. Clin Nutr 2011; 30: 49-53.

20. Ljungqvist O, van Gossum A, Sanz ML, de Man F. The European fight against malnutrition. Clin Nutr 2010; 29: 149150.

21. Brasil RDC/ANVISA. Brasil RDC/ANVISA No. 63 , de 6 de julho de 2000 - Aprova o Regulamento Técnico para fixar os requisitos mínimos exigidos para a Terapia de Nutrição Enteral. http://e-legis.anvisa.gov.br/leisref/public/showAct. php2010.

22. Saunders J, Smith T. Malnutrition: causes and consequences. Clin Med 2010; 10: 624-627.

23. Rufenacht $U$, Ruhlin $M$, Wegmann M, Imoberdorf R, Ballmer $P E$. Nutritional counseling improves quality of life and nutrient intake in hospitalized undernourished patients. Nutrition 2010; 26: 53-60.

24. Beck AM, Balknas UN, Furst P, Hasunen K, Jones L, Keller $U$, et al. Food and nutritional care in hospitals: how to prevent undernutrition - report and guidelines from the Council of Europe. Clin Nutr 2001; 20: 455-460.

25. Prieto MB, Cid JL. Malnutrition in the critically ill child: the importance of enteral nutrition. Int J Environ Res Public Health 2011; 8: 4353-4366.

26. Guidelines for the use of parenteral and enteral nutrition in adult and pediatric patients. J Parenter Enteral Nutr 2002; 26: 1SA-138SA.

27. Kreymann KG, Berger MM, Deutz NE, Hiesmayr M, Jolliet $P$, Kazandjiev G, et al. ESPEN Guidelines on Enteral Nutrition: Intensive care. Clin Nutr 2006; 25: 210-223.

28. Corish CA, Kennedy NP. Protein-energy undernutrition in hospital in-patients. Br J Nutr 2000; 83: 575-591.

29. Stolic RV, Trajkovic GZ, Peric VM, Stolic DZ, Sovtic SR, Aleksandar JN, et al. Impact of metabolic syndrome and malnutrition on mortality in chronic hemodialysis patients. $J$ Ren Nutr 2010; 20: 38-43. 